\title{
DISABILITIES AND PROGRESS IN A DYSPHASIC UNIVERSITY STUDENT \\ BY
}

\author{
M. B. ELVIN and R. C. OLDFIELD
}

\section{From the Department of Neurology, Radcliffe Infirmary, Oxford and the Institute of Experimental Psychology, Oxford}

The relations between language and thought in the normal person, and the connexion between the forms of their disturbance in the dysphasic, are questions which have aroused much discussion and little conclusion. But at least it would seem clear that the nearer an individual's daily occupation approaches to the purely intellectual, the more it is likely to be impeded by even a mild degree of dysphasia. It is tempting to suppose that if an intellectual occupation were nevertheless pursued, the study of its products in the form of written material might contribute to an understanding of the relations of thought and language, at least in respect of their modes of breakdown. So uncommon is it, indeed, for any degree of dysphasia, however slight, to leave the patient still capable of attempting to lead a chiefly intellectual life that little has been reported of such cases.* Apart from the accidents of war dysphasia is a condition encountered chiefly among those of established occupation, or those whose days of active occupation are over. The significant problems of prognosis and rehabilitation scarcely go beyond the question of whether or not the patient can maintain and exercise skills long since acquired-skills whose progressive aspects may for some time have fallen into abeyance. And the analysis of intellectual deterioration and its relationship to linguistic breakdown is much complicated by the existence of ingrown habitual practices, whose disentanglement from constructive adaptations is not easy to effect. The case of a healthy and highly intelligent young man, destined for one of the learned pro-

\footnotetext{
*In Head's (1926) series, for example, one patient is reported to have had a university education, and one to have been a medical student before injury. In neither of these is there any suggestion of student before injury. In neither of these is there any suggestion of
their return to intellectual occupations. In one other case (No. 2) their return to intellectual occupations. In one other case (No. 2) it is reported that the patient re-learnt Hindustani, and in general
showed a remarkable power of re-acquiring knowledge. Head showed a remarkable power of re-acquiring knowledge. Head
remarks that he might superficially have passed for a normal man Alajouanine (1948) gives an interesting account of three cases of dysphasia in elderly people who had followed intellectual or artistic vocations. Only one of these (an artist) was able effectively to continue his previous activities.
}

fessions and educated accordingly, who becomes the victim of dysphasia between school and university, is, however, a very different one. He presents, for instance, prognostic and rehabilitation problems of great delicacy: if encouraged and enabled to pursue his earlier plans of becoming a university student, he will be engaged for at least two years in work that is continually novel and constructive, and almost exclusively intellectual. Moreover it is work which demands the written expression of thought upon a succession of occasions. The study of this written material, in conjunction with a clinical assessment of his condition throughout the period, can scarcely fail to be of interest. Not the least interesting is the relation of thought to language, especially the question of how far there is interaction, and how far mere parallelism, or independence, in their breakdown and recovery.

\section{Case History}

Lieut. K (Case No. 16134), who came of a professional family, was educated at a public school and won an open scholarship to the university before joining the Army in 1942. His chief interest at school had been in classics, and he had intended continuing their study at the university, though he had actually won his scholarship in history. After sustaining a head injury he found difficulty in recalling Latin and Greek, especially the latter, and this fact made him decide to read history.

On September 7, 1944, at the age of 23 , the patient sustained a deep penetrating injury from a shell fragment in the left temporal region. The wound was excised and sutured on September 8, 1944, when 2-3 oz. of pulp and blood clot were removed. The wound healed by first intention. The $x$-ray tracing in Fig. 1 shows the extent of the resulting bone-defect which measured $10 \times 4 \mathrm{~cm}$. approximately. Retrograde amnesia was momentary. Post-traumatic amnesia lasted for about four weeks. On becoming aware of his surroundings he thought that he must be in a foreign country as speech had no meaning. This only lasted for a few days. He also failed to recognize his mother at first, and thought she must be a social worker. 


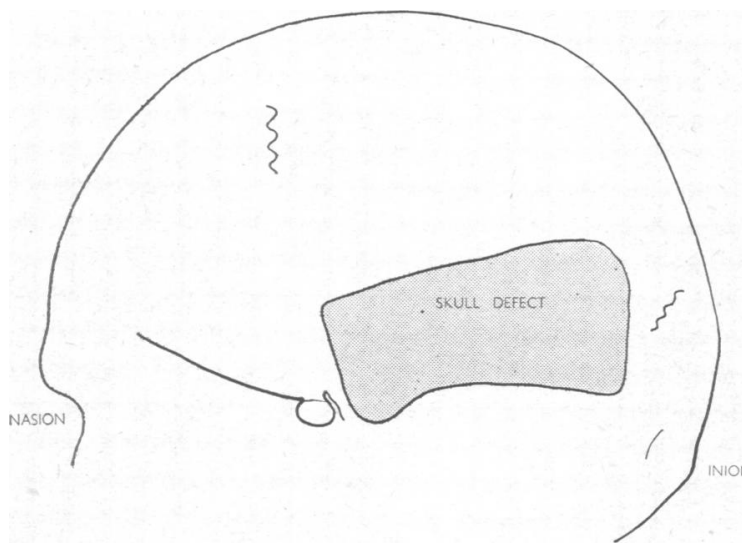

FIG. 1.-Tracing of lateral skull radiograph showing site of post-operative skull defect.

He sustained a complete and permanent homonymous hemianopia to the right. He had two fits (in December, 1945, and July, 1946) beginning in the right hand and progressing to a generalized convulsion. $\mathrm{He}$ is still (1950) taking phenobarbitone. For a brief period after the injury he suffered from complete right hemiplegia, but this had cleared up by December, 1944. The available evidence suggests that he was predominantly righthanded, though he had played tennis with the left hand, and was in the habit of using it for a few other activities.

By the time he entered the university in the autumn of 1945 , the paralysis and the speech were much improved. $\mathrm{He}$ was able to row in his college boat and to take a fairly normal part in university life. In December, 1946, however, he still used a stick in walking, partly because he was not fully adjusted to his hemianopia (and complained of a wandering right eye), and partly because his right foot was still troublesome. Speech in December, 1946, was rapid (as it had always been, he said), and very irregular in tempo. He felt difficulty in framing what he wanted to say, and this was increased by any delay or any attempt to think over the expression of his ideas before utterance. The urgency of his speech decreased during the two and a half years that followed, but was still noticeable in June, 1946. The hemianopia remained essentially unchanged. He appeared eventually to make a good adaptation to the difficulty. By the time he left the university, the complaint of a wandering eye had ceased, and he was able to move about normally.

$\mathrm{He}$ remained at the university for seven terms, and was placed in the second class in the final honours examination for the shortened war course. For about six months afterwards he worked in a museum as a student, with the idea of looking for a job in a local history museum later. Difficulty in being accepted for insurance cut short his efforts to obtain such work under a local authority, but in the autumn of 1948 he was awarded a research studentship in London seventeenth century history. The award was for one year and has been renewed once.

In December, 1946, he was given a number of psychometric tests. On the Wechsler-Bellevue scale his vocabu- lary was at a very superior level, and there was no impairment in arithmetical computation and reasoning, in immediate retention for digits, or for visual-constructive tasks. His weighted scores were : vocabulary, 18 ; arithmetic, 17 ; block-designs, 16 . On the digit-symbol sub-test his performance was relatively poor, his weighted score being 8 . Immediate retention for verbal material was above average, though, presumably, relatively constricted for his general intellectual level, and he found considerable difficulty in learning digits or verbal material beyond his immediate retention span. Immediately after reading a passage through he could recall a number of items nearly as great as the norm, but he felt the task to be difficult, and his performance was poor in relation to his general ability. He could reproduce argument more correctly than narrative. For both these types of material reproduction was more coherent after five minutes delay than immediately after presentation, although some points might be forgotten in the interval. On neither the sorting (Vigotsky) nor Rorschach tests were there any marked peculiarities, though on the former there was some tendency to abandon one principle for another before completing the sorting, and on the latter his drive to organize his ideas tended to be poorly maintained. In verbal reasoning (Burt-problems) he was generally quick and correct, but would sometimes overlook a detail in the longer problems and then find it difficult or impossible to spot his omission on re-reading. He was also inclined to become too involved in his own view of the problem, either as regards form or matter, to be able to return to the facts as stated, despite a real effort and intention to do so.

At this time comprehension of speech in ordinary conversation seemed normal. When required to sort objects according to a verbally formulated dichotomy he made no errors that he did not himself correct in 70 choices, but obviously found the task exhausting. His spontaneous speech was rapid, though punctuated with many hesitations, some a-a-a-ing, and some repetition of initial s's. In answer to specific questions speech became more hesitant and awkward. Pronunciation was correct, and there was no actual misuse of words in conversation. He showed some hesitation in naming objects. Finding the word he wanted when trying to express an idea of any complexity, as in giving a definition, was a task of some difficulty. Reading aloud was accurate except for a slight tendency to drop or alter the endings of longer words, and to confuse short words such as " to ", " the ", "for", errors which he generally corrected. Hesitations were conspicuous and were associated with an inability to see what lay ahead, the consequence of his hemianopia. Difficulty in comprehension only appeared in dealing with long and involved statements where visual and retentive disabilities seemed to be of considerable consequence. His speed of comprehending visual symbols briefly presented seemed to be normal, although the right half of the field was frequently missed. Given the time to think of each word, spelling was good, though he was apt to be doubtful of double letters. Writing was rapid, legible, and grammatical. When tired, however, he was still apt to misuse words, and commit grammatical errors. 
Such disabilities became evident in writing long essays, though not in the test interview. He described his memory for events in the recent past as vague, and found it difficult to recall much of what had happened during the previous summer holiday which had been spent abroad. He complained of a liability to make conflicting appointments, and then forget both.

In the past, his interest had quite largely centred around verbal activity. Words amused him, and he was given to playing with them in epigram and rhyme. He met his linguistic difficulties in good spirit, created social capital out of jokes about his speech errors, and made considerable efforts to adapt his ambitions to his now restricted capacities. (He had originally intended to read for the Bar.) He entered into all the social, intellectual and athletic activities of which he was still capable. In December, 1946, however, he was very conscious of the difficulty he was finding in learning and remembering, and in writing satisfactory essays. He became somewhat distressed by his inability to use notes made on his holiday reading on account of their incomprehensibility. And in general he was wondering in an anxious way about his prospects. After a careful clinical and psychological assessment, however, he was encouraged to continue reading for his degree. At this time he very kindly agreed to submit for study some of his written work.

\section{The Written Material Submitted for Analysis}

The written material selected for analysis was the following : (1) an essay written in his last term at school before joining the army; (2) two letters written in November, 1944, three months after injury ; (3) eight essays chosen from those written each week between October, 1945, and June, 1947 ; (4) two trial examination papers; (5) an essay written voluntarily at our request in January, 1948 , six months after taking his degree.

\section{Analysis of the Material}

General. - The following quotation from his school essay is given as an example of his written work before his injury. It was written at the age of 17 on "The Conquest of Egypt".

Now the Cabinet was faced with the decision of leaving Gordon to his fate, or sending a large army to save him. They had not the courage to do either. At last public opinion forced them to send Wolseley to get him back. Wolseley reached Egypt, battled his way up the Nile, sent forward advance guards and pushed on for all he was worth. A minor reverse held them up for three days. They reached Khartoum two days after Gordon was killed.

No spelling or grammatical errors occur in this essay which is easy to read, intelligent and coherent, though not brilliant. Language is used with facility and some dramatic effect. At the same time it ought perhaps to be noted that a few minor defects of expression are shown, and these are of a kind which occurs in a much more severe form in the later material. It would be more correct in the last sentence to say ". . . after Gordon had been killed." And, in the two preceding sentences, there is a certain confusion of number which leaves the meaning rather imprecise.

Extracts from two letters indicate the degree of difficulty he experienced in written expression three months after the injury.

I hope this will come to you for the right address I am attempting. I do want to hear fo you and how you are making as it is ages since $I$ heard of you since the last I spoke to you.

As you bullied me to promise a letter, I will do so and do youself as good as mine will be. A Very cryptic remark? I'll have to get on to you. How are you ? Do you answer? No? Well the answer doesn't matter.

There are examples here of the use of omnibus words (e.g., " do" and " make") to cover limitations of vocabulary, of the misuse of prepositions (e.g., "for the right address"), of repetitions and omissions, and of a change of grammatical structure in the middle of a sentence.

The first essay was nearly incomprehensible without much re-reading, interpolation, and interpretation on the part of the reader. For the following six months essays continued to be very difficult to follow. Nevertheless, from the beginning they were shapely. A basic pattern of introduction, argument, and conclusion could, with sufficient $\Omega$ effort, be seen to emerge from the matter, although the proper connexions between paragraphs, and often between phrases and sentences, were not expressed or were expressed incorrectly. Some measure of real comprehension and planning must have been applied in writing the essays from October, 1945, onwards, even though the patient felt that he had not " really understood the subject ", and that his own essays were of little use to him in refreshing his memory. The difficulty he found in using his essays and the notes he took on reading during the summer of 1946, was, however, only in part due to their " incomprehensibility". By June, 1946, the essays were, in fact, moderately clear and coherent despite errors. But in re-reading such essays, though he found the opinions expressed clear enough, he was disturbed by the apparent vagueness of the facts, and by the failure of what he had written to bring them to mind again. Consequently he had to re-study each subject for examination purposes. By contrast, he found himself able to recall opinion, but in December, 1946, he could never be sure whether it was his own opinion or somebody else's. By 1950 he was sure that it was in fact always his own opinion that was so recalled.

Essays written up to the end of 1946, and indeed into 1947, were written quickly in order to put his 
ideas down before he lost the gist of what he wanted to say. On the whole he felt that they were the more coherent the quicker he wrote, and the less he really had to say. On the other hand spelling mistakes and minor omissions were more likely to occur with speed. When reading the essays aloud to his tutor he could, and would, make alterations and corrections. Nevertheless, it was not until the late spring of 1946 that his tutor felt that he began to see "what the essays were driving at". During the autumn of 1945 he was writing two essays a week on different periods of history, one on the Restoration in which he was interested, the other on the Anglo-Saxon period in which he was not. The periods were about equally new to him. The first group of essays are the harder to follow, but have more substance and show more evidence of thought. The latter are simpler, shorter, more factual, and are expressed in a rather juvenile way.

Length of Essays and Errors.-Table I shows the length of the representative essays, together with the types of error. Though there is no steady increase, and it would be unreasonable to consider such an increase to be in itself a sign of improve- ment, the last essay of the university group is in fact nearly twice the length of the first. The last, also, has fewer errors than the first, and the majority of the minor errors occur towards the end, possibly indicating fatigue.

In order to allow comparison throughout the series, the original numbers have all been converted into the number of errors per 10,000 words (to the nearest whole number). An interesting point which emerges from Table $I$ is that the trend of improvement is marked most clearly in the fewer wrong prepositions, and in the decreasing number of awkward, indeterminate expressions, and spelling errors. In other cases, those for instance of the use of the wrong verb, and of a shift of grammatical form, no clear trend is present at all, unless it consists in a tendency for performance to be at its worst in the middle of the series of essays. Total errors are shown graphed against time in Fig. 2, and prepositional errors in Fig. 3.

Spelling errors decreased, on the whole, during the year and a half covered by the essays for tutorials, but there was a sudden increase when limited time conditions were imposed as in the trial paper (No. 9). This seemed to indicate lack of time for correction, rather than renewed breakdown due

TABLE I

PROPORTIONAL ERRORS IN A SERIES OF ESSAYS

\begin{tabular}{|c|c|c|c|c|c|c|c|c|c|c|c|c|c|c|c|c|}
\hline 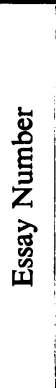 & 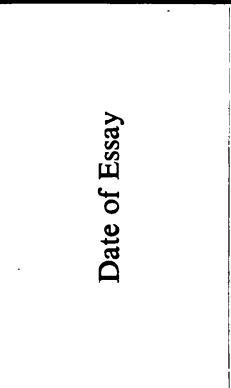 & 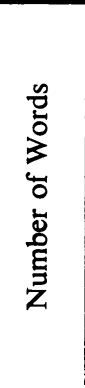 & 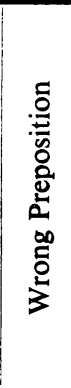 & 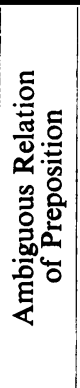 & 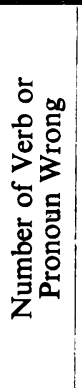 & 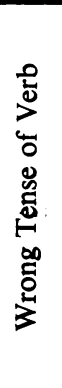 & 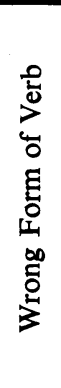 & 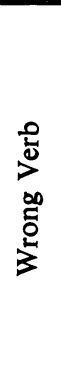 & $\begin{array}{l}\underline{E} \\
\frac{5}{00} \\
\frac{0}{8} \\
\dot{d}\end{array}$ & 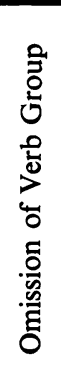 & 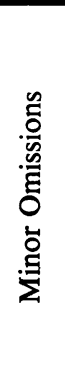 & 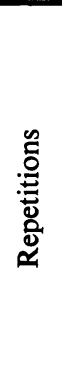 & 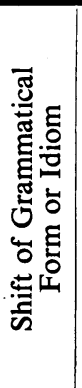 & 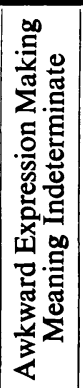 & 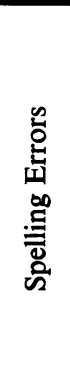 & 号 \\
\hline 1 & October, 1945 & 1380 & 72 & 7 & 22 & 7 & 29 & 7 & 0 & 7 & 22 & 7 & - & 72 & 80 & 332 \\
\hline 2 & January, 1946 & 1495 & 34 & 7 & 7 & 7 & 7 & 7 & 13 & 0 & 0 & 7 & 13 & 67 & 60 & 229 \\
\hline 3 & May, 1946 & 2100 & 10 & 0 & $\mathbf{0}$ & 0 & 10 & 10 & 0 & 10 & 5 & 5 & 0 & 19 & 38 & 107 \\
\hline 4 & June, 1946 & 2200 & 23 & 0 & 18 & 0 & 0 & 0 & 0 & 5 & 14 & 0 & 5 & 9 & 32 & 106 \\
\hline 5 & October, 1946 & 2114 & 10 & 0 & 24 & 0 & 5 & 14 & 0 & 0 & 18 & 5 & 5 & 10 & 10 & 101 \\
\hline 6 & December, 1946 & 1605 & 13 & 0 & 6 & 6 & 6 & 6 & 0 & 6 & 6 & 6 & 6 & 6 & 0 & 67 \\
\hline 7 & January, 1947 & 1605 & 0 & 0 & 13 & 6 & 6 & 25 & 0 & 6 & 0 & 0 & 13 & 0 & 25 & 94 \\
\hline 8 & February, 1947 & 2537 & 20 & 4 & 20 & 0 & 12 & 8 & 0 & 4 & 20 & 0 & 8 & 4 & 20 & 120 \\
\hline \multirow[t]{2}{*}{ c } & January, 1948 & 1500 & 7 & 0 & 14 & 0 & 0 & 7 & 0 & 0 & 0 & 0 & 0 & 14 & 7 & 49 \\
\hline & \multicolumn{2}{|l|}{ Total } & & 18 & 124 & 26 & 75 & 84 & 13 & 38 & 85 & 30 & 50 & 201 & 272 & 1205 \\
\hline
\end{tabular}


to fatigue or strain. The errors appear scattered throughout the paper, as they do in the essays written

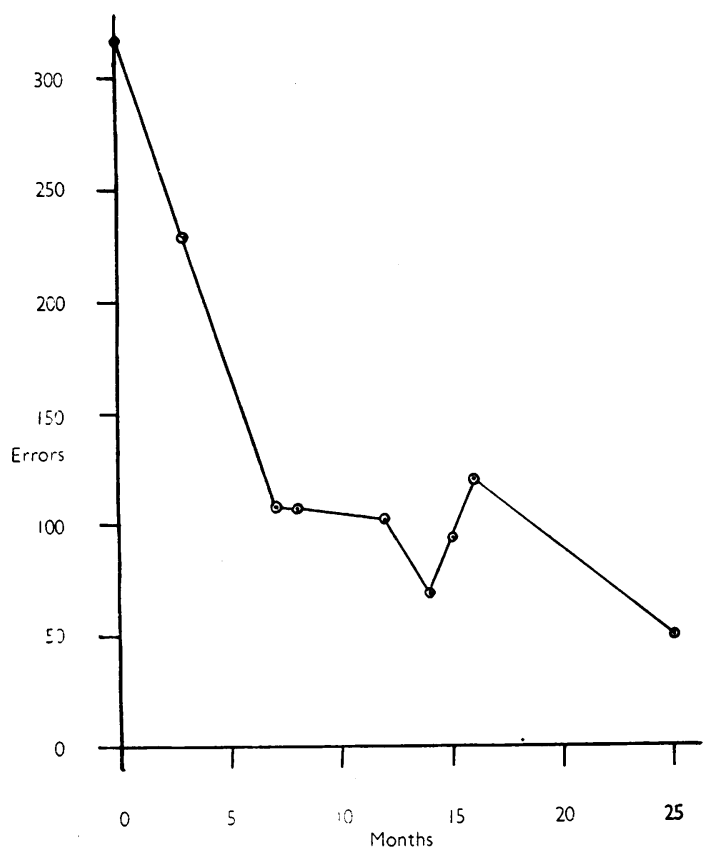

FIG. 2.-Graph of total errors in the series of essays.

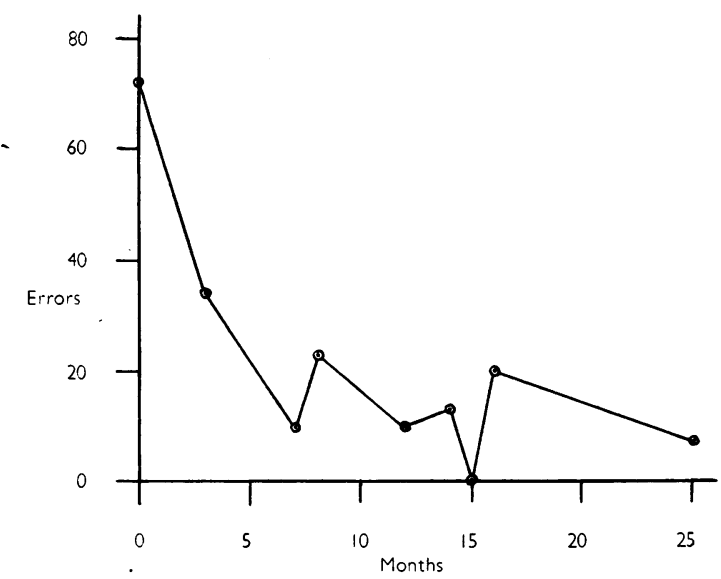

FIG. 3.-Graph of prepositional errors in the series of essays.

at leisure, but in the latter they would generally be corrected on re-reading. The only uncorrected error in the voluntary essay of January, 1948, is " dependant " for " dependent", one so common as to be of little significance. In any case, the patient provided written evidence that his spelling before injury had not been flawless.
Vocabulary.-Table II shows the number of different words used in the first 994 words of essays 1 and 8, analysed according to parts of speech. These figures show a $67 \%$ increase of vocabulary over this period, and this is in keeping with the great decrease in verbal repetition noticeable in the first essay.

". . . changes were made to make the Castles under Royal Control ... soon to make Pitt in control".

". . . consummation was consummated".

“. . . parties were continually pressed by the continual pressure of the Crown".

Secondly it appears from this table that nouns and adjectives show the greatest absolute, as also the highest percentage, increase. The relative numbers of parts of speech, however, remain remarkably constant. The more precise denotation possible with the greater range of nouns and adjectives brought into play is reflected in the abatement of confusion caused by the use of over-general words. Conjunctions also show a high percentage increase, doubling in number during the year and a half, and this allows a much more explicit relation of ideas. A considerable increase in adverbs, many of them temporal, had the same beneficial effect.

The actual misuse of conjunctions was comparatively rare: the relations between sentences and clauses were more commonly left unexpressed. In this respect conjunctions differed considerably from prepositions. The latter increased only slightly in variety (they were rarely omitted even in the earliest essays) but their misuse was constant at first, tended easily to recur with fatigue later, and was not entirely eliminated even by 1948 in the voluntary essay written at leisure. The reason for this difference is not clear, though it might perhaps be suggested that omission of conjunctions is not so destructive of the formal structure of the sentence as is that of prepositions.

It must not be supposed, in analysing the patient's vocabulary at a given stage of recovery, that his restricted use of words was wholly the product of their loss or unavailability. Perseverative tendencies, both in respect of words and of phrases, may prevent the employment of words which would otherwise play a part in his expression.

Major Factors Causing Incomprehensibility.-The chief factors which make the early essays difficult to understand are the following.

The Misuse of Single Words.-The construction following such a word is often not anticipated by the reader.

"The State church became not under State control." 
TABLE II

VARIETY OF WORDS USED IN ESSAYS 1 (OCTOBER, 1945) AND 8 (FEBRUARY, 1947)

\begin{tabular}{|c|c|c|c|c|c|c|c|c|}
\hline \multirow{2}{*}{\multicolumn{3}{|c|}{ Part of Speech }} & \multicolumn{2}{|c|}{ Essay 1} & \multicolumn{2}{|c|}{ Essay 8} & \multirow[b]{2}{*}{$\begin{array}{l}\text { Absolute } \\
\text { Increase }\end{array}$} & \multirow[b]{2}{*}{$\begin{array}{l}\text { Percentage } \\
\text { Increase }\end{array}$} \\
\hline & & & $\begin{array}{l}\text { No. of } \\
\text { Different } \\
\text { Words }\end{array}$ & Percentage & $\begin{array}{c}\text { No. of } \\
\text { Different } \\
\text { Words }\end{array}$ & Percentage & & \\
\hline Articles. . & .. & .. & 3 & - & 3 & - & 0 & 0 \\
\hline Prepositions & . & . & 19 & 5 & 22 & 4 & 3 & 16 \\
\hline Pronouns & .. & $\therefore:$ & 11 & 3 & 15 & 3 & 4 & 36 \\
\hline Nouns (Prope & & .. & 25 & 7 & 43 & 7 & 18 & 72 \\
\hline Nouns (Comn & non) & $\ldots$ & 115 & 31 & 197 & 32 & 82 & 71 \\
\hline Verbs & . & . & 70 & 19 & 95 & 16 & 25 & 36 \\
\hline Adjectives & . & .. & 77 & 21 & 160 & 25 & 83 & 108 \\
\hline Adverbs & .. & .. & 33 & 9 & 52 & 9 & 19 & 58 \\
\hline Conjunctions & $\ldots$ & . & 12 & 3 & 24 & 4 & 12 & 100 \\
\hline Total & . & .. & 365 & & 611 & & 246 & 67 \\
\hline
\end{tabular}

“... of its negative attitude, the most important problem arose ..."

"The Commons had long been at issue over the Crown on matters of finance."

Failure to State the Main Point of a Paragraph.Comment and criticism are given without adequate indication of the subject.

Lack of Verbal Precision.-Too often " general" words are used, when a wider vocabulary would have provided the right word in the right place.

"The negative aspect of Parliament ..."

" He was in all things supreme."

" ". . failure of negociations encouraged Cromwell to let the matter turn into war."

"Yet he brought about an even more powerful disrupting factor to the Whigs."

A similar fault is the failure to qualify a reference sufficiently :-

"Whig theory" (referring to the Whig theory of an aristocratic Junta).

"They fell back on the 1640 attitude."

Inappropriate Use of Words.-This seems in part to be simple perseveration, affording a solution to the difficulties of a restricted vocabulary, but the patient's delight in epigram perhaps also encourages the tendency.

"... . parties reversed in their attitude to external affairs ... systems of electoral representation was not reversed."

“. . . not examine details [i.e. to judge the value of
Wolseley's later work] but the results. Then later ... the details of his work had more effect."

In the second example the logical failure is only apparent. In fact the second " detail" is short for " the effect on detail ".

Telescoping Ideas.-There was a tendency to telescope ideas, and their logical connexion either of content or grammar was omitted.

“. . . final outbreak of disturbance that caused Henry to submit was his own contact with foreign affairs."

Such telescoping may apply to an alteration in the writer's point of view, and will then often involve a change of grammatical structure.

"The long eclipse of the Whigs only emerged when a Whig Party under Grey was built up."

In many cases, especially in the first term's essays, the awkwardness was composite in origin, and could be subsumed under more than one of the above headings.

"The existence of James as a Roman Catholic intensified by his marriage ...."

(Shift, telescoping, ? omission.)

"It made pressure of the Crown brought to a head but it did not clear the issue."

(Omission, misuse of word, ? shift of approach.)

" The final failure of North made the King to surrender at last" followed by ". . . by refusing to allow a Parliament to be held in his absence he at once made any such Parliament to be obviously rebellious."

(Over-general words, ? shift in construction.) 
Minor Errors.-In addition to these major sources of confusion, there are other types of error. These, though less confusing to the reader, demand alertness if they are not to be allowed to disrupt the meaning. Among these minor errors are the omission of minor words, the ambiguous relation of pronouns, word repetition, the use of an incorrect grammatical form or of a wrong tense, failure to make verb or pronoun agree in number, and minor shifts of grammatical construction not in themselves very confusing.

\section{Condition at the End of the Essay Series}

In March, 1948, the patient was given the digit symbol test again. He made six more substitutions, and the same two half errors as he had in December, 1946. Though there had been a great change in his general adjustment to the field defect during this time, it probably still handicapped him on a test of this type. By this date, his immediate retention span for verbal material had increased so that he could repeat the appropriate Babcock sentence with ease. Verbal learning beyond this span, however, still presented difficulty. He no longer had the trouble in reproducing a moderately complicated grammatical structure that he experienced in December, 1946. At that time he was apt to introduce alterations of a mildly confabulatory nature which were based, apparently, upon the use of visualization to surmount verbal difficulty. In March, 1948, these were no longer evident. But omissions of structurally important words occurred, as did the introduction of synonyms. These errors tended to recur in a perseverative fashion. He was, however, able to reproduce the content of verbal passages more coherently and fully. An increased capacity for rote retention assisted him in this, but he was still liable to rely upon a word sequence rather than upon retention of the trains of ideas expressed. When this tendency led him into absurdity he would correct himself. He showed an improved capacity to carry out verbal reasoning tests of the type devised by Burt. He clung less tenaciously to his first incorrect conclusion, and on re-reading the problem more quickly grasped relevant data previously overlooked and so was able to consider its implications without getting confused with his previous line of reasoning.

In February, 1950, he reported some difficulty in learning new technical terms. He complained that he constantly forgot the sources of his information, and had in consequence to make frequent fresh starts. Dates, even when he was constantly using them, slipped easily from his mind. As regards day-to-day memory, he found that he was still inclined to forget appointments, though less frequently than three years before. He had a "permanent uncertainty about the date and the day of the week". His memory of the past was, he said, more complete and accurate than it had been, though recall did not produce much "emotional excitement", perhaps because the work he had been doing was unexciting compared with his activity during the war years. The contrast between war and peace made comparison difficult, but he thought that he lived " very much from day to day . . . with little sense of anticipation in that I do not make any advance plans, and the fact that I am going to do or see anything new does not produce any excitement". Events during the war " have a far sharper photographic impression on my mind".

He was seen again in November, 1950, and there appeared to have been little change in his condition, in so far as it could be elicited by interview and a few psychometric tests. His speech was still subject to blockages demanding the introduction of circumlocutory and redundant material if the flow of expression was to be preserved. Object-naming was not free from error and circumlocution. The written expression of material just studied by reading was very adequate, but was carried out at a furious speed. He made a few spelling errors, mostly corrected, chiefly of substitution of phonetically similar consonants. Grammar, syntax, and logical form might be regarded as normal (if sometimes slipshod), considering the haste with which the tasks were carried out, and the written versions showed evidence of intelligent compression of the originals. He again noted greater ease in reproducing argument than narrative, and this was borne out by his performance. On the digit-symbol test there was evidence of a further slight improvement, his weighted score having risen to 11 .

On questioning him regarding his present life and work, much the same points were elicited as on the previous occasion, and indeed it seemed that he had reached a stable attitude towards himself and his affairs, so that he confines his activities to those in which he can reach an adequate level of adjustment or achievement without drawing upon the finer points of skill which are now impaired. How successful he is in carrying out his historical work it is impossible to say, but it is certainly of a character which intellectually would have made but slight demands upon a person of his intelligence if unimpaired. He himself feels that his present capacities are adequate to his work, but acknowledges that his overall rate of working is probably no more than a third of what it was previous to injury. He is frequently constrained to break off 
work and turn for a time to a distraction such as The Times crossword puzzle (which he finds himself quite competent to tackle). In short, he appears to have reached, at least temporarily, an adequate, if constricted, adaptation. Whether this phase will be succeeded by one of fresh expansion remains to be seen.

\section{Discussion}

We have already remarked upon the meagre fruits of theory about the relations of thought and language. John Dewey (1933) has said: "The conviction that language is necessary to thinking (is even identical with it) is met by the contention that language perverts and conceals thought", and, he continues, broadly three different views have found their supporters. The first is that the two are identical. The second that words are necessary only for the communication of thought, not for thought itself : the third that language, though not identical with thought, is yet necessary to it. This last, commonly upheld, must at once raise the question of the precise manner in which language plays its role in the processes of thinking. In the special field of linguistic breakdown, this question becomes, "In what way does a disturbance of the language mechanisms impede thinking?" and, "Is the disturbance of thought capacity in dysphasics thus only secondary to the language breakdown?"

To these questions, Henry Head offered one possible answer. For him, whatever is worthy of the name of thought is not an act of "simple matching ", but demands the intervention of symbolic processes between stimulus and response. Aphasia is basically a disorder of these symbolic mechanisms. That it manifests itself chiefly in the linguistic field is but a reflection of the predominance of language among the other symbolic systems used by man. The patient is " lame in thinking " because the mechanisms by which he thinks are out of order. In somewhat similar fashion, the economic life of a country would be very gravely disturbed if its monetary and banking system were largely destroyed overnight. The movements of currency and credit do not constitute trade. Barter operations, though clumsy and limited in scope, are possible without them. But in practice a monetary and banking system is necessary to modern commerce as we know it. Without it, too, payments in actual coin become meaningless. So, for Head, both disturbance of thought and breakdown of overt language alike arise from the destruction of the more basic symbolic mechanisms. His conclusion is, perhaps, chiefly of value in its emphasis upon the immense complexity of the processes which underlie both thought and language, by contrast with the relative simplicity of the verbal transactions we observe. Sentences, like payments in actual coin, are limited in variety by the available material. Neither reveals the richness of the organization behind them.*

Other writers, of whom the outstanding example is Arnold Pick, have approached the problem of the relation of language to thought in somewhat different terms. They have asked by what sequence of processes the thought is formulated into a sentence suitable for overt expression. As expounded in his earlier work (1913) these comprise four stages : (1) the mental attitude, diffuse if intellectually informed; (2) the thought-schema, in which the material is psychologically differentiated; (3) the schema of the phrase, in which the syntactical and grammatical form of what is to be uttered is present ; and (4) the choice of words to fill in the phraseschema and complete the sentence. Pick's justification for the adoption of this kind of framework $\dagger$ lies in his conviction that clinically the varieties of aphasia are in accordance with it. Certainly it emphasizes the difference between those disorders which manifest themselves chiefly in a disturbance of content, and those, such as agrammatism, where the disruption is one of form.

Useful as conceptions such as these may be in the analysis of language disorders, they are clearly incomplete inasmuch as they offer little in the way of hypotheses regarding the manner in which thought itself takes place. The views of Selz $(1922,1924)$, who obtained from experiments on the thoughtprocesses themselves independent evidence of the part played by schematic frameworks, go some way towards extending Pick's findings in the required direction. Bartlett's (1932) extension of Head's theory of schemata is perhaps equally relevant.

But, apart from the shortcomings already noted, current theories in this field suffer from another grave defect, and it is this which observations on our patient throw into relief. "As soon as we attempt to express our thoughts even to ourselves," writes Head (1926), " we re-arrange them and drastically prune away redundant and incoherent features. For the purpose of articulated speech or writing this process is carried out still more ruthlessly . . . the results of unrestricted thinking are refined and ordered in accordance with logical canons." Certainly this is one essential aspect of the formulatory

\footnotetext{
*It should, perhaps, be made clear that Head did not employ this economic analogy, but it seems not inappropriately to express the essence of his view.

†Pick is at some pains, especially in his later writings (1931), to make it clear that this sequence of stages is flexible, and by no means always fully followed. There may, for instance, be condensation, and thought may proceed at levels other than the first. Van Woerkom (1921) has proposed a similar set of stages, which places greater emphasis on the active-synthetic and analytic-nature of the second stage.
} 
process. But there are others, less comforting in their implications, which have not received the attention of which they are worthy. At these Head hints when he remarks: "The superb logician may have difficulty in expounding his ideas and we are familiar with the practised speaker whose words are jejune of thought". The introduction of coherence and the pruning of redundancies are too often not the sole outcome of formulation. Something may be lost from the thought itself. Habitual verbal forms, and conventional syntactical schemes, eagerly offer themselves, as Delacroix (1924) and others have pointed out, to spare the pains of thought. The element of originality or profundity the original shadowy thought perhaps possessed may be beyond the skill or patience of the speaker to formulate. Instead a compromise completion of the task is reached, in terms of empty and conventional, if sometimes elegant, expression. This tendency will be reinforced where, as is frequently the case with expressive dysphasics, continuity of utterance is imperative if breakdown and blockage are to be avoided. Alternatively, something of the essence of the thought may be preserved only at the expense of obscure and complex verbal guise which, even in the normal individual, may amount to syntactical error. There is a basic antagonism between thought and expression which always demands some compromise. There may be conflict to the extent that the individual's aspirations become involved on one side or the other.

When we consider the series of essays written by our patient, we may ask how far defects of expression can be distinguished from those of thought, and to what extent both can be seen to be the outcome of some common failure of intellectual organization. As improvement takes place, do the two types of difficulty clear up in parallel fashion? It may be remarked at once that, while the evidence points to a general parallelism of progress, there are occasions when his thought appears to be clearer and more adequately structured than his faulty language allows him to express. On others a deceptive cłarity of expression may conceal an underlying woolliness of thought. That thinking was often clearer than expression was demonstrably true when prepositions were misused and conjunctions omitted. He was frequently prepared during 1947 to defend his misuse of prepositions, at the same time indicating in other ways that the idea was perfectly clear. He could explain the relationship of phrases and sentences which he failed, by omitting a conjunction, sufficiently to relate. Similarly the denotation of many over-general nouns and expressions was in fact more precise to him than might appear to the reader, as would become clear from his amplifications in conversation. The same could be said of some telescoping and shifts of grammatical structure. Confused expression at any particular point, in fact, did not necessarily indicate a corresponding confusion of thought. It was often simply the outcome of the inadequate linguistic resources available to him at that moment. The actual expression achieved would then be a compromise reached by lowering his standards of correctness, and even by the acceptance of pathological tendencies such as perseveration. On the other hand, expression could superficially be clearer than thought. The clearest of his early essays were those about subjects in which he was not strongly interested. According to his own account he would, in such cases, take the leading ideas from his reading and reproduce them glibly without much comprehension of their implications and relations. Something which did not engage his personal intellectual interest equally did not evoke the repressive criticisms and linguistic inhibitions which few normal writers escape. In his own words :

"I could see that there were ideas A, B, and C. I could use $A, B$, and $C$ in an Euclidean way, finishing up with a Q.E.D., without really knowing what A, B, and $C$ implied. For instance, I might have known that growth of the powers of the thegns was an important fact, and that this led to the success of William the Conqueror. But I would not have seen why it was important, nor would I have any idea how, when and why the thegns had become important, nor even what I meant by thegn. I don't now. But I could put down correctly $\mathbf{A}+\mathbf{B}+\mathbf{C}=\mathbf{D}$. It certainly meant that even at the time of reading my sources I didn't really understand the point, though I could see that it was one."

Clearly some comprehension is needed to make a sensible selection of points, and to follow a plan $A+B+C=D$. But his understanding of the situation was superficial, hardly going deeper than a commonplace acceptance of the verbal terms of the argument and of their logical outcome. Expression was coherent but simple.

It is not without interest to compare the peculiarities of the patient's verbal expression with the difficulties of thought which he experienced, as judged by the quotation. A number of parallels suggest themselves.

There is a correspondence between the tendency to use words of over-general meaning in expression, such as " matter" and " thing" (associated with a small number of substantives and adjectives in the earlier essays), and the lack of specificity and structure in an idea; for example, the lack of explicit understanding of what thegns were and did, notwithstanding the appropriate use of the word thegn in argument. 
The inadequate articulation of sentences, clauses, and paragraphs which results from a paucity of conjunctions, the wrong use of prepositions, and the omission of connecting statements, may perhaps find a parallel in the incomplete connexion of ideas which he describes when, for instance, he remarks that the importance of the growth of the power of the thegns was not evident to him. His thinking lacks the formal precision which in expression is afforded by the words " therefore", " now", " because of", and " on the other hand".

The changes in grammatical structure which are apt to occur part of the way through a sentence ("forgetting how a sentence started") might be held to correspond with the difficulty experienced in keeping a total problem in mind while still considering the implications of part of the data. This difficulty was shown in his performance on the verbal reasoning tests. It is also indicated in his feeling that much reading was a bad preparation for writing the essay (" The less preparation and reading I do, the better the essay ", 1946).

Speed, both in achieving expression and in understanding a situation, were of great importance to him. Fear of forgetting the beginning, whether of a sentence or of a train of thought, was one element in his desire for speed. Another was the avoidance of interference by the search for appropriate words on the one hand, and by the seduction of intellectual red-herrings on the other. The structure of both speech and thought was to some degree evanescent. In thinking he sought for structures ; for instance he complained of the lack of a clear chronological framework in Anglo-Saxon history on which to hang events. In the effort to replace the insight which he lacked, he would adopt an artificial structure not really grounded in his thought, and this would often prove inadequate to the solution of the particular problem he was engaged on. In the same way, the grammatical structure of the beginning of a sentence was apt not to anticipate its end appropriately.

Coherence in thought and speech had their best opportunity if deliberation were avoided. Deliberation might involve, for instance, search for an appropriate word, or the consideration in greater detail of evidence hitherto partially neglected. In these cases confusion was likely to arise. But, characteristically, this inadequacy of structure resulted in rigidity rather than in weakness of thought and expression. If, in reasoning, a form grew out of the data, it was difficult for the patient to treat it as tentative. Either it broke down when further evidence was noted, or it persisted rigidly and contra-indications were ignored. In verbal expression, the tendency to rigidity appeared in the form of stock phrases, of phrases personally favoured by the patient, or of phrases recently used. These were the alternative to breakdown of expressive activity. Both in thought and expression, the patient seemed to lack normal freedom to manipulate his own mental processes. The healthy individual can and does treat each production of his mental activity as the object of criticism and refinement, so arriving at an apt response. The patient cannot achieve such smooth convergence upon the appropriate act. If he is to decide, or to express, at all, it can often only be done by accepting incompletely evident concepts, or inaccurate grammatical forms.

Certainly in general the patient gave evidence of corresponding difficulties in the field of thought and expression, but it is at the same time clear that these two skills are to some extent independent of one another, inasmuch as the compromise in his performance might be reached at the expense of one or other of them. The freer he was from the intellectual difficulties aroused by his own interests, the greater was his capacity to express himself correctly. Where, on the other hand, his more personal intellectual powers were challenged, all his expressive disabilities were aroused in the effort to do justice to his thought.

These considerations suggest, perhaps, that where the attempt is made to re-educate the dysphasic by exercise in expression, the subject matter should be chosen so as to evoke interest, but not touch too closely the more basic of the patient's preoccupations. Where, on the other hand, it is desired to rehabilitate the capacity for thought, too close an insistence on its formal expression may defeat the main object.

Our main conclusions which emerge from the study of this patient's behaviour are.

(1) The common basis, which Head attributes to the intellectual and linguistic functions is borne out in so far as both in their breakdown and their recovery they exhibit phases of a broadly similar character. It must be remembered in this connexion, however, that the dysphasia exhibited by our patient was of a predominantly expressive character, and any assessment of his thinking is therefore to some extent conjectural. Nevertheless it has seemed to us possible to distinguish to some extent the respects in which his difficulties were to be attributed to breakdown of the symbolic mechanisms utilized in thinking from those more especially connected with linguistic expression. But it is clear that, according to Head's view, no absolute distinction of this kind can be made.

(2) The implicit, unavoidable, conflict involved in the attempt to formulate and express the products of thought is more clearly shown in a patient of this 
kind than in the normal individual. The resulting compromise is less apt, sometimes doing justice to the thought at the expense of clarity in expression, at others accepting conventional forms of expression which replace the thinker's individual contribution by socially contrived clichés. In the latter case it is later difficult, as he reported, for the patient to decide whether the views so expressed are his own or those of others.

(3) Progress in the restitution of expressive function, as shown in the essay series, is clearly marked by a decrease in prepositional errors, and it is suggested that this is paralleled by increasing capacity to use valid structures in the manipulation of ideas.

\section{Summary}

The case is described of a young, healthy, and highly intelligent man who sustained a penetrating head injury producing an initially severe dysphasia, and subsequently took up the open scholarship he had previously won at the university and obtained second class honours.

A number of the essays which the patient wrote as a student are analysed and his progress traced in respect both of linguistic and intellectual skills. His condition was also assessed at intervals clinically and by psychometric methods.

Linguistic and intellectual improvement showed a parallel course, but the effects of the antagonistic demands of thought and expression were also noted.

Some consideration is given to the bearing of the findings on current views regarding the relations of language and thought.

We should like to express our gratitude to the patient for his generosity in making his written work available for analysis, and for his ready response to all our enquiries. We have also to thank Sir Hugh Cairns and Dr. W. Ritchie Russell for permission to make use of the clinical material, and to publish this case.

\section{REFERENCES}

Alajouanine, T. (1948). Brain, 71, 229.

Bartlett, F. C. (1932). " Remembering." Cambridge.

Delacroix, H. (1924). “ Le Langage et la Pensée.” Paris.

Dewey, J. (1933). " How We Think." New York.

Head, H. (1926). "Aphasia and Kindred Disorders of Speech." Cambridge.

Pick, A. (1913). "Die agrammatischen Sprachstörungen." Berlin.

(1931). In " Handbuch der normalen pathologischen Physiologie ", ed. A. Bethe, G. von Bergmann, G. Embden, and A. Ellinger., vol. 15 pt. 2, p. 14161524. Berlin.

Selz, O. (1922). "Zur Psychologie des produktiven und reproduktiven Denkens und des Irrtums." Bonn. (1924). "Die Gesetze der produktiven und reproduktiven Geistestätigkeit." Bonn.

Woerkom, W. van (1921). J. Psychol. norm. path. 18, 730-751. 